\title{
QUANTITATIVE ELECTROENCEPHALOGRAPHIC STUDIES OF ANOXIA IN HUMANS; COMPARISON WITH ACUTE ALCOHOLIC INTOXICATION AND HYPOGLYCEMIA ${ }^{1}$
}

\author{
By GEORGE L. ENGEL, JOSEPH P. WEBB, AND EUGENE B. FERRIS \\ (From the Departments of Internal Medicine and Psychiatry, College of Medicine, \\ University of Cincinnati, Cincinnati)
}

(Received for publication February 26, 1945)

That disturbances in consciousness, and consequently in behavior, are produced by anoxia is well known. The clinical picture is essentially that of delirium, a syndrome in which we have pointed out that the primary psychologic symptom is a reduction in the level of consciousness (1). With moderate or severe degree of anoxia the changes are grossly obvious.

The evaluation of the harmful effects of mild degrees of anoxia, however, has proven extremely difficult due to the lack of accurate methods of measuring such effects. Such measurements are of obvious importance to aviation medicine and are of interest in studies of the earliest changes in delirium. So far, the most satisfactory methods have concerned changes in visual functions. Various performance and psychological tests have all proven relatively unsatisfactory due to the wide range of individual responses, doubtless influenced by motivation and emotional factors. In such studies statistical analyses of a large number of subjects indicate that significant degrees of impairment of performance begin around 12,000 feet $(483.3 \mathrm{~mm} . \mathrm{Hg})$.

Numerous investigators have reported the effects of anoxia, hypoglycemia, and various drugs on the electroencephalogram, but for the most part, these studies have been concerned with the more marked changes. The demonstration of a close relationship between changes in frequency distribution in the electroencephalogram and levels of consciousness (1) and the development of a quantitative method for analyzing electroencephalographic frequency spectra (2) offer a practical approach to the study of cortical function during mild to moderate degrees of anoxia. The

\footnotetext{
1 The work described in this paper was carried out under contract, recommended by the Committee on Medical Research, between the Office of Scientific Research and Development and the University of Cincinnati.
}

study of the normal electroencephalogram with this method reveals a continuous range of frequency change during variations within the physiological zone of blood sugar, oxygen, and acidbase balance. Contrary to prevailing notions, the transition between this physiological zone and a pathological zone is subtle and not abrupt. Studies with hypoglycemia, alcohol, and other toxic materials have clearly demonstrated that the degree of change in frequency is of far more importance than the appearance of any particular wave frequency (i.e., delta waves). For example, equivalent degrees of acute alcoholic intoxication with comparable reduction in the level of consciousness in different individuals may be associated with widely different frequency distribution, but the degree of change in frequency from the control record is always comparable for all subjects (3). These data clearly demonstrate the inadequacy of the crude methods of interpretation of the electroencephalogram which depend upon the appearance of abnormally slow waves ( 2 to 7 per second), and explain why previous brain wave studies have not proven fruitful in the evaluation of intermediary zones of acute anoxia, where gross changes in the level of consciousness are not usually apparent.

\section{METHODS AND MATERIAL}

Seven medical students and 3 staff members acted as subjects for the experiments. They were exposed in the decompression chamber to simulated altitudes of 10,000 to 16,000 feet breathing air, and 39,000 to 42,500 feet breathing 100 per cent oxygen for varying periods of time up to 3 hours. A Bulbulian type 14 demand mask modified for constant flow, was used. When several altitudes were tested on the same flight, possible cumulative effects were avoided by having the subjects breathe at a higher than normal oxygen tension for 10 minutes before starting the next period of anoxia. Blood sugar levels were obtained at frequent intervals since the frequency spectra vary with changes in blood sugar (2). Blood sugar was determined by the Folin-Wu colori- 
TABLE I

The effect of exposure to altitudes of 10,000 to 16,000 feet on the E.E.G. frequency spectra

This illustrates the magnitude of the spectral shift and the consistency with which the mean frequency diminished in 4 subjects exposed 11 times.

\begin{tabular}{|c|c|c|c|c|c|c|c|c|c|c|c|c|c|}
\hline \multirow{4}{*}{$\begin{array}{l}\text { Name and date } \\
\text { EF } \\
11-30-44\end{array}$} & \multirow{2}{*}{\multicolumn{2}{|c|}{ Altitude }} & \multirow{4}{*}{$\begin{array}{c}\text { Time } \\
\text { minutes }\end{array}$} & \multicolumn{8}{|c|}{ E.E.G. frequency spectra } & \multirow{4}{*}{$\begin{array}{c}\begin{array}{c}\text { E.E.G. } \\
\text { mean } \\
\text { freq. }\end{array} \\
\\
\\
8.98 \\
8.51 \\
8.36 \\
8.28 \\
8.77\end{array}$} & \multirow{4}{*}{$\begin{array}{c}\begin{array}{c}\text { Arm } \\
\text { vein } \\
\text { blood } \\
\text { sugar }\end{array} \\
\begin{array}{c}\text { mgm. } \\
\text { per cen } \\
105\end{array} \\
95\end{array}$} \\
\hline & & & & LVF* & 12 & 11 & 10 & 9 & 8 & 7 & 6 & & \\
\hline & feet & $m m . H g$ & & \multicolumn{8}{|c|}{ percentage of waves per second } & & \\
\hline & $\begin{array}{c}\text { Ground } \\
10,000 \\
14,000 \\
16,000 \\
\text { Ground }\end{array}$ & $\begin{array}{l}747 \\
523 \\
446 \\
412 \\
747\end{array}$ & & & & & $\begin{array}{r}23 \\
9 \\
7 \\
8 \\
20\end{array}$ & $\begin{array}{l}55 \\
43 \\
35 \\
28 \\
41\end{array}$ & $\begin{array}{l}19 \\
39 \\
46 \\
49 \\
35\end{array}$ & $\begin{array}{r}3 \\
8 \\
11 \\
14 \\
4\end{array}$ & $\begin{array}{l}1 \\
1 \\
1\end{array}$ & & \\
\hline $\begin{array}{l}\text { EF (1) } \\
10-14-44\end{array}$ & $\begin{array}{c}\text { Ground } \\
10,000 \\
10,000 \\
\text { Ground }\end{array}$ & $\begin{array}{l}747 \\
523 \\
523 \\
747\end{array}$ & $\begin{array}{r}5 \\
60 \\
5\end{array}$ & 1 & & 2 & $\begin{array}{l}18 \\
13 \\
12 \\
18\end{array}$ & $\begin{array}{l}60 \\
42 \\
43 \\
62\end{array}$ & $\begin{array}{l}20 \\
40 \\
34 \\
19\end{array}$ & $\begin{array}{l}2 \\
5 \\
8 \\
1\end{array}$ & & $\begin{array}{l}8.94 \\
8.63 \\
8.65 \\
8.97\end{array}$ & $\begin{array}{l}100 \\
95\end{array}$ \\
\hline $\begin{array}{l}\text { EF (2) } \\
10-15-44\end{array}$ & $\begin{array}{c}\text { Ground } \\
10,000 \\
12,000 \\
12,000 \\
\text { Ground }\end{array}$ & $\begin{array}{l}747 \\
523 \\
483 \\
483 \\
747\end{array}$ & $\begin{array}{r}5 \\
5 \\
60 \\
5\end{array}$ & & & $\begin{array}{l}2 \\
1 \\
1 \\
5\end{array}$ & $\begin{array}{l}33 \\
21 \\
19 \\
23 \\
30\end{array}$ & $\begin{array}{l}45 \\
53 \\
53 \\
53 \\
49\end{array}$ & $\begin{array}{l}20 \\
23 \\
24 \\
20 \\
16\end{array}$ & $\begin{array}{l}3 \\
3 \\
3\end{array}$ & & $\begin{array}{l}9.17 \\
8.92 \\
8.91 \\
8.99 \\
9.24\end{array}$ & 98 \\
\hline $\begin{array}{l}\mathrm{EF}(3) \\
10-20-44\end{array}$ & $\begin{array}{c}\text { Ground } \\
10,000 \\
12,000 \\
14,000 \\
14,000 \\
\text { Ground }\end{array}$ & $\begin{array}{l}747 \\
523 \\
483 \\
446 \\
446 \\
747\end{array}$ & $\begin{array}{r}5 \\
5 \\
5 \\
60 \\
5\end{array}$ & $\begin{array}{l}1 \\
1\end{array}$ & & $\begin{array}{l}4 \\
2 \\
2\end{array}$ & $\begin{array}{l}31 \\
19 \\
18 \\
13 \\
13 \\
34\end{array}$ & $\begin{array}{l}47 \\
41 \\
45 \\
45 \\
36 \\
47\end{array}$ & $\begin{array}{l}16 \\
35 \\
31 \\
31 \\
37 \\
16\end{array}$ & $\begin{array}{r}1 \\
5 \\
6 \\
8 \\
11 \\
1\end{array}$ & 2 & $\begin{array}{l}9.22 \\
8.74 \\
8.75 \\
8.69 \\
8.48 \\
9.20\end{array}$ & 93 \\
\hline $\begin{array}{l}\text { EF (4) } \\
11-12-44\end{array}$ & $\begin{array}{l}\text { Ground } \\
14,000 \\
14,000 \\
14,000 \\
14,000 \\
14,000 \\
\text { Ground }\end{array}$ & $\begin{array}{l}747 \\
446 \\
446 \\
446 \\
446 \\
446 \\
747\end{array}$ & $\begin{array}{r}5 \\
30 \\
60 \\
120 \\
180 \\
5\end{array}$ & $\begin{array}{l}1 \\
1 \\
1 \\
1 \\
2 \\
2 \\
2\end{array}$ & & $\begin{array}{l}3 \\
1 \\
1 \\
1\end{array}$ & $\begin{array}{r}19 \\
18 \\
10 \\
12 \\
7 \\
12 \\
26\end{array}$ & $\begin{array}{l}49 \\
41 \\
37 \\
36 \\
37 \\
35 \\
47\end{array}$ & $\begin{array}{l}25 \\
33 \\
42 \\
38 \\
41 \\
32 \\
22\end{array}$ & $\begin{array}{r}3 \\
7 \\
10 \\
12 \\
13 \\
18 \\
2\end{array}$ & & $\begin{array}{l}8.94 \\
8.71 \\
8.47 \\
8.51 \\
8.39 \\
8.45 \\
9.02 \\
\end{array}$ & $\begin{array}{r}100 \\
95 \\
100 \\
95\end{array}$ \\
\hline $\begin{array}{l}\text { GE (1) } \\
11-12-44\end{array}$ & $\begin{array}{c}\text { Ground } \\
14,000 \\
14,000 \\
14,000 \\
14,000 \\
14,000 \\
\text { Ground }\end{array}$ & $\begin{array}{l}747 \\
446 \\
446 \\
446 \\
446 \\
446 \\
747\end{array}$ & $\begin{array}{r}5 \\
30 \\
60 \\
120 \\
180 \\
5\end{array}$ & 1 & & $\begin{array}{l}1 \\
1\end{array}$ & $\begin{array}{l}49 \\
32 \\
27 \\
20 \\
17 \\
21 \\
42\end{array}$ & $\begin{array}{l}44 \\
53 \\
43 \\
49 \\
49 \\
44 \\
48\end{array}$ & $\begin{array}{r}6 \\
14 \\
26 \\
28 \\
30 \\
31 \\
9\end{array}$ & $\begin{array}{l}3 \\
3 \\
4 \\
4\end{array}$ & & $\begin{array}{l}9.45 \\
9.20 \\
8.95 \\
8.86 \\
8.79 \\
8.82 \\
9.35\end{array}$ & $\begin{array}{r}95 \\
\\
95 \\
95 \\
105\end{array}$ \\
\hline $\begin{array}{l}\mathrm{GE}(3) \\
10-20-44\end{array}$ & $\begin{array}{c}\text { Ground } \\
10,000 \\
12,000 \\
14,000 \\
14,000 \\
\text { Ground }\end{array}$ & $\begin{array}{l}747 \\
523 \\
483 \\
446 \\
446 \\
747\end{array}$ & $\begin{array}{r}5 \\
5 \\
5 \\
60 \\
5\end{array}$ & $\begin{array}{l}1 \\
1 \\
1 \\
2 \\
2 \\
2\end{array}$ & & & $\begin{array}{r}28 \\
9 \\
16 \\
6 \\
10 \\
26\end{array}$ & $\begin{array}{l}55 \\
50 \\
45 \\
39 \\
34 \\
48\end{array}$ & $\begin{array}{l}15 \\
35 \\
33 \\
39 \\
38 \\
19\end{array}$ & $\begin{array}{r}1 \\
5 \\
5 \\
10 \\
14 \\
5\end{array}$ & $\begin{array}{l}4 \\
2\end{array}$ & $\begin{array}{l}9.12 \\
8.64 \\
8.73 \\
8.34 \\
8.37 \\
8.97\end{array}$ & 89 \\
\hline $\begin{array}{l}\text { DS } \\
12-10-44\end{array}$ & $\begin{array}{c}\text { Ground } \\
10,000 \\
14,000 \\
16,000 \\
\text { Ground }\end{array}$ & $\begin{array}{l}747 \\
523 \\
446 \\
412 \\
747\end{array}$ & $\begin{array}{l}30 \\
30 \\
30 \\
10\end{array}$ & $\begin{array}{l}2 \\
1\end{array}$ & & $\begin{array}{r}13 \\
10 \\
5 \\
3 \\
9\end{array}$ & $\begin{array}{l}60 \\
44 \\
45 \\
25 \\
56\end{array}$ & $\begin{array}{l}22 \\
33 \\
34 \\
43 \\
30\end{array}$ & $\begin{array}{r}5 \\
11 \\
15 \\
23 \\
5\end{array}$ & 5 & 1 & $\begin{array}{l}9.81 \\
9.53 \\
9.40 \\
8.95 \\
9.69\end{array}$ & \\
\hline $\begin{array}{l}\mathrm{MR}(1) \\
12-3-44\end{array}$ & $\begin{array}{c}\text { Ground } \\
10,000 \\
14,000 \\
16,000 \\
\text { Ground }\end{array}$ & $\begin{array}{l}747 \\
523 \\
446 \\
412 \\
747\end{array}$ & $\begin{array}{r}30 \\
30 \\
30 \\
5\end{array}$ & $\begin{array}{l}6 \\
6 \\
7 \\
6 \\
7\end{array}$ & $\begin{array}{l}8 \\
3 \\
1 \\
1 \\
7\end{array}$ & $\begin{array}{r}56 \\
49 \\
15 \\
8 \\
42\end{array}$ & $\begin{array}{l}28 \\
33 \\
53 \\
34 \\
37\end{array}$ & $\begin{array}{r}2 \\
9 \\
22 \\
46 \\
7\end{array}$ & $\begin{array}{l}2 \\
5\end{array}$ & & & $\begin{array}{r}10.74 \\
10.49 \\
9.90 \\
9.51 \\
10.53\end{array}$ & 85 \\
\hline $\begin{array}{l}\text { MR (2) } \\
12-10-44\end{array}$ & $\begin{array}{c}\text { Ground } \\
10,000 \\
14,000 \\
16,000 \\
\text { Ground }\end{array}$ & $\begin{array}{l}747 \\
523 \\
446 \\
412 \\
747\end{array}$ & $\begin{array}{l}30 \\
30 \\
30 \\
10\end{array}$ & $\begin{array}{l}11 \\
11 \\
11 \\
10 \\
11\end{array}$ & $\begin{array}{l}6 \\
3 \\
3\end{array}$ & $\begin{array}{r}48 \\
32 \\
15 \\
3 \\
40\end{array}$ & $\begin{array}{l}32 \\
42 \\
47 \\
38 \\
34\end{array}$ & $\begin{array}{r}3 \\
13 \\
22 \\
32 \\
12\end{array}$ & $\begin{array}{r}5 \\
16\end{array}$ & 1 & & $\begin{array}{r}10.64 \\
10.28 \\
9.81 \\
9.29 \\
10.38\end{array}$ & \\
\hline
\end{tabular}

- Low voltage fast activity. 
metric method, which includes non-glucose reducing substances. We selected subjects whose electroencephalograms showed good alpha rhythm and less than 10 per cent low voltage fast activity, since quantitative analysis of frequency change is far more accurate in such records.

All electroencephalograms consisted of bipolar frontooccipital tracings. The method of analysis of the electroencephalograms is that described in detail in the report already cited (2). This consisted of counting the number of waves per second interval (utilizing the ruled paper supplied by Mr. Albert Grass) for 200 consecutive seconds. The distribution of frequencies per second was then expressed as a percentage of the whole. A complete wave was one which returned at least two-thirds of the way to the base line. A wave which crossed the line dividing adjacent one-second intervals was counted in the interval containing more than half the wave. Small superimposed waves were not counted. In general, it was found advisable to make full use of the high frequency filter to damp the superimposed fast oscillations of very low voltage (some of which were of muscle origin) so that the basic sine waves would have sharper definition. Stretches of low voltage fast activity were designated as such (LVF) and no attempt was made to count the individual waves, which were often not countable. Such an analysis yields the percentile distribution of waves per second (rather than the distribution of wave lengths). In addition to expressing the result in terms of the distribution of waves per second intervals (frequency spectrum), it was also found of value to calculate the arithmetical mean frequency from this distribution. $^{2}$ This yields a number, the mean of the number of waves per second interval, which allows far more precise comparison of frequency changes under the different conditions than would be possible by comparison of the frequency spectra alone. Since the amount of low voltage fast activity cannot be included in the calculation of mean frequency, the advantage of selecting records with little or no voltage fast activity is obvious.

\section{RESULTS}

Table I and Figure 1 illustrate that significant shifts to slower frequencies in the electroencephalographic spectra are demonstrable at 10,000 feet $(522.6 \mathrm{~mm} . \mathrm{Hg}$ ) and that this shift becomes more marked with increasing altitudes up to 16,000 feet $(411.8 \mathrm{~mm}$. $\mathrm{Hg})$. This shift is not visible on inspection of the record alone. Most of the shift is demonstrable within $\mathbf{5}$ minutes of reaching altitude and is maximal within 15 to 30 minutes, there being relatively little change thereafter up to 3 hours. The degree of shift at 10,000 feet for 30 to 60 minutes among 4 individuals (6 trials) ranged from 0.25 to 0.47 ; at 16,000 feet for 30

2 This technique was suggested by Dr. Charles Stevens. minutes the degree of shift ranged from 0.65 to 1.35 (4 individuals, 5 flights). In general, the greater shifts occurred in the records with faster control frequencies (Figure 1). Upon return to ground level, the pattern was usually restored to the preflight value within 10 minutes. The factors involved in this lag were not clarified.

Comparative studies on 6 subjects breathing air and breathing 100 per cent oxygen revealed that breathing air at 10,000 feet $(522.6 \mathrm{~mm}$. $\mathrm{Hg}$ ) was equivalent to breathing 100 per cent oxygen at 39,000 feet $(147.6 \mathrm{~mm}$. $\mathrm{Hg}$ ) (see Figure 2) and that breathing air at 16,000 feet $(411.8 \mathrm{~mm}$. $\mathrm{Hg})$ was approximately equivalent to breathing 100 per cent oxygen at 42,500 feet $(124.8 \mathrm{~mm}$. $\mathrm{Hg})$ (see Figure 3 ) as regards the degree of shift in the electroencephalographic frequency spectra. Other altitudes were not studied. Again the electroencephalograms with the higher control frequencies tended to show somewhat greater frequency shifts. The development of abdominal distention or of decompression sickness at the higher altitudes did not directly alter the electroencephalogram as had already been noted in earlier studies (4), but it did limit the time at altitude to 10 to 15 minutes so that the frequency changes may not have been fully developed.

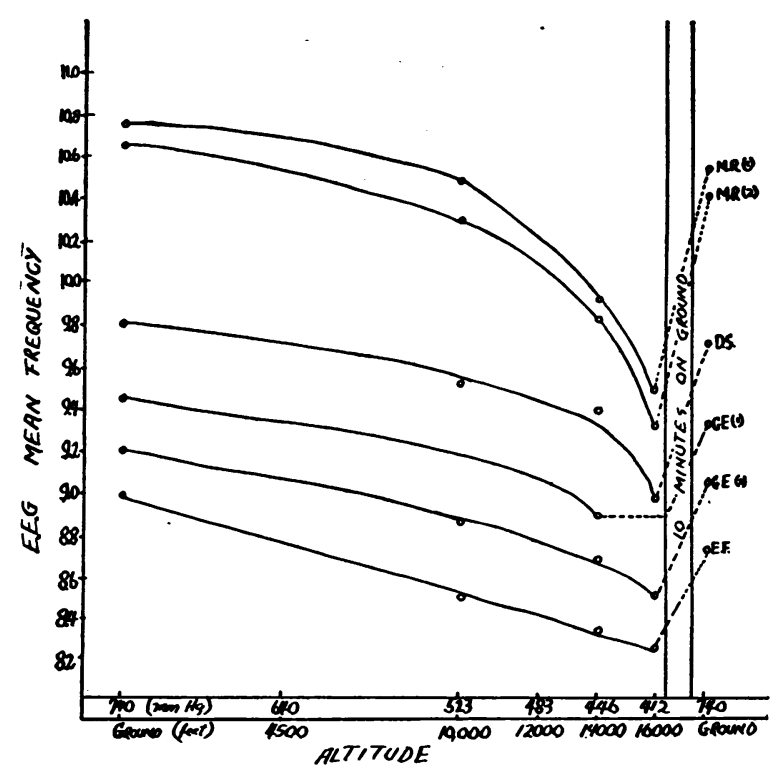

Fig. 1. Changes in Electroencephalographic Mean Frequency with Decreasing Atmospheric Pressure (INCREASING ALTITUDE) 


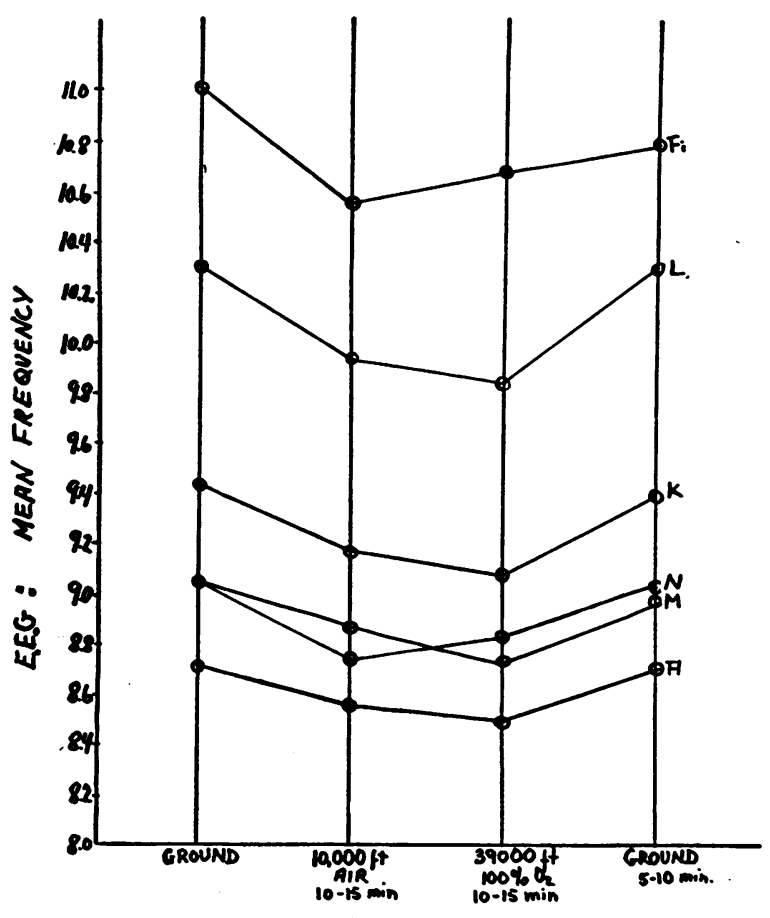

Fig. 2. Comparative Changes in Electroencephalographic Mean Frequency at 10,000 Feet Breathing AIr and at 39,000 Feet Breathing 100 Per Cent OXYGEN

Since acute alcoholic intoxication, and to a lesser degree hypoglycemia, are more familiar experiences than anoxia to both physician and layman, it was felt worthwhile to compare with anoxia the electroencephalographic frequency shifts in those conditions in the same subjects. Hypoglycemia was produced in 4 subjects by the intravenous administration of 0.1 units of insulin per kgm. body weight in the fasting state. This reduced blood sugars to the range of 35 to 49 mgm. per cent at which levels the subjects experienced mild hypoglycemic symptoms, with weakness and light-headedness, but no loss of consciousness. On another occasion, acute intoxication was produced in the same subject by the ingestion of $100 \mathrm{ml}$. of 95 per cent ethyl alcohol. The alcohol was consumed within a 5-minute period in the fasting state. Electroencephalograms were repeated when the subjects noted the first subjective symptoms, which was within 45 to 55 minutes after ingestion. Two subjects, consuming larger amounts of alcohol, were followed through the stage of severe and gross intoxication back to recovery. The results are illustrated in Figures 4 and 5. It was found that the degree of change in the electroencephalogram upon exposure to 16,000 feet $(411.8 \mathrm{~mm}$. $\mathrm{Hg}$ ) was roughly similar to that seen during the period of development of first symptoms of alcoholic intoxication and during reduction of blood sugar to 44 to $49 \mathrm{mgm}$. per cent. The degree of change was considerably greater during severe intoxication and in the one instance where blood sugar fell to $35 \mathrm{mgm}$. per cent. Blood sugars of 75 to $80 \mathrm{mgm}$. per cent appeared to be associated with changes equivalent to 10,000 to 12,000 feet ( 522.6 to $483.3 \mathrm{~mm}$. $\mathrm{Hg}$ ).

Certain observations on the behavior of the subjects subjected to anoxia, alcohol and hypoglycemia may be pertinent. All the subjects had made many flights to altitudes of 35,000 to 38,000 feet ( 178.7 to $154.9 \mathrm{~mm}$. $\mathrm{Hg}$ ) and although they had had no experience with anoxia, they regarded 16,000 feet with equanimity. At 16,000 feet all the subjects were aware of slight darkening of vision, vague light headedness, and uneasiness. Two subjects, $K$. and L., became somewhat bois-

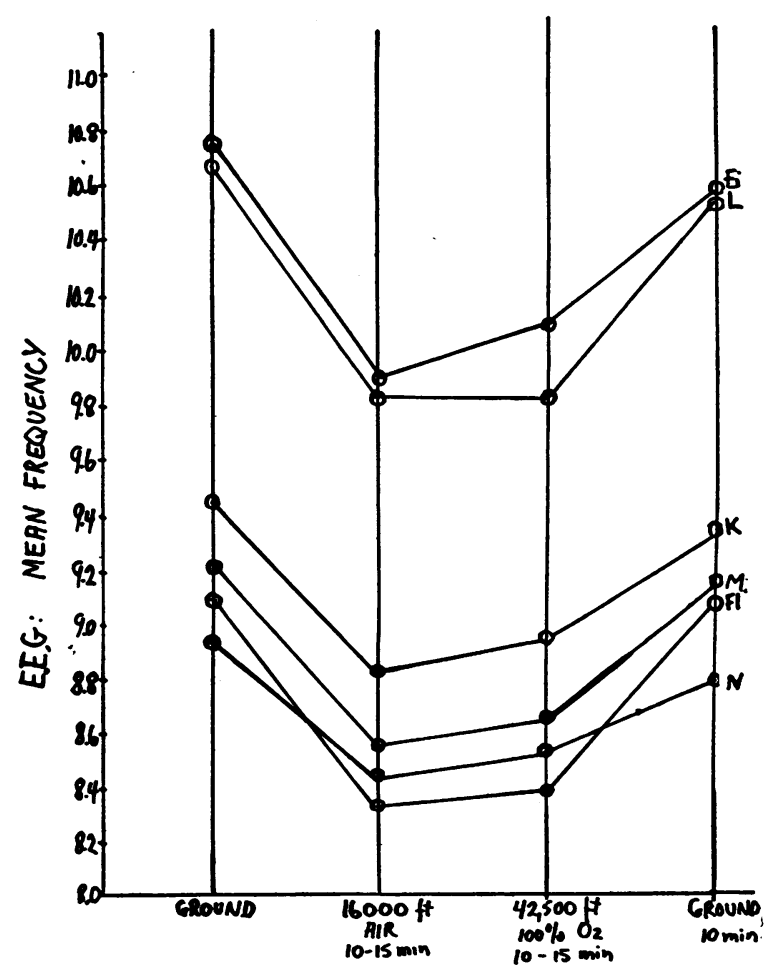

Fig. 3. Comparative Changes in Electroencephalographic Mean Frequency at 16,000 Feet Breathing Air and 42,500 Feet Breathing 100 Per Cent Oxygen 
terous and overtalkative, while $M$. and $N$. remained outwardly unperturbed. During the alcohol experiment $K$. became the caricature of the "happy drunk," a change which began almost before the dose of alcohol had been administered! L. also laughed and joked a great deal, but could be quiet and restrained at will. M. was quiet and unobtrusive, but shortly after the electroencephalogram was taken he developed a reaction of marked withdrawal and bursts of aggressive behavior. $\mathrm{N}$. showed no obvious visible behavior disturbance yet insisted that he felt drunk and would not want to drink any more. During the hypoglycemia experiments, all the subjects became anxious at the time of developing symptoms. The anxiety was most marked in M., least in $N$. (who had lower blood sugar), and $\mathrm{K}$. and $\mathrm{L}$. in contrast to their behavior during the alcoholic experiment were quiet, anxious, and repeatedly demanded re-

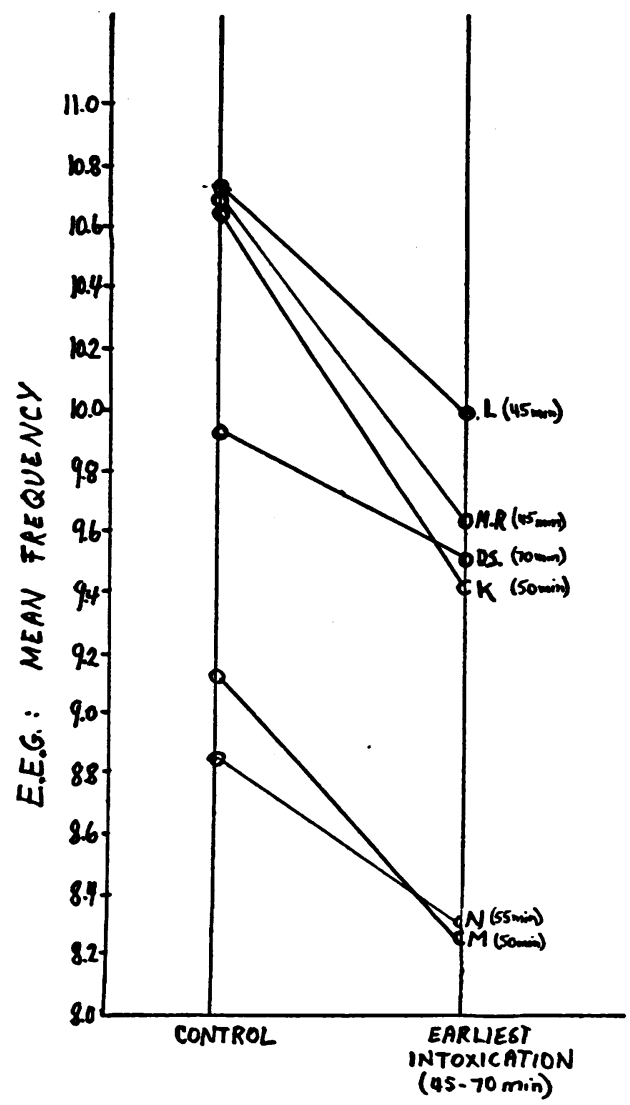

Fig. 4. Changes in Electroencephalographic Mean Frequency Occurring During Eariest Signs of INTOXICATION (SAME SUBJECTS AS IN PREVIOUS FIGURES)

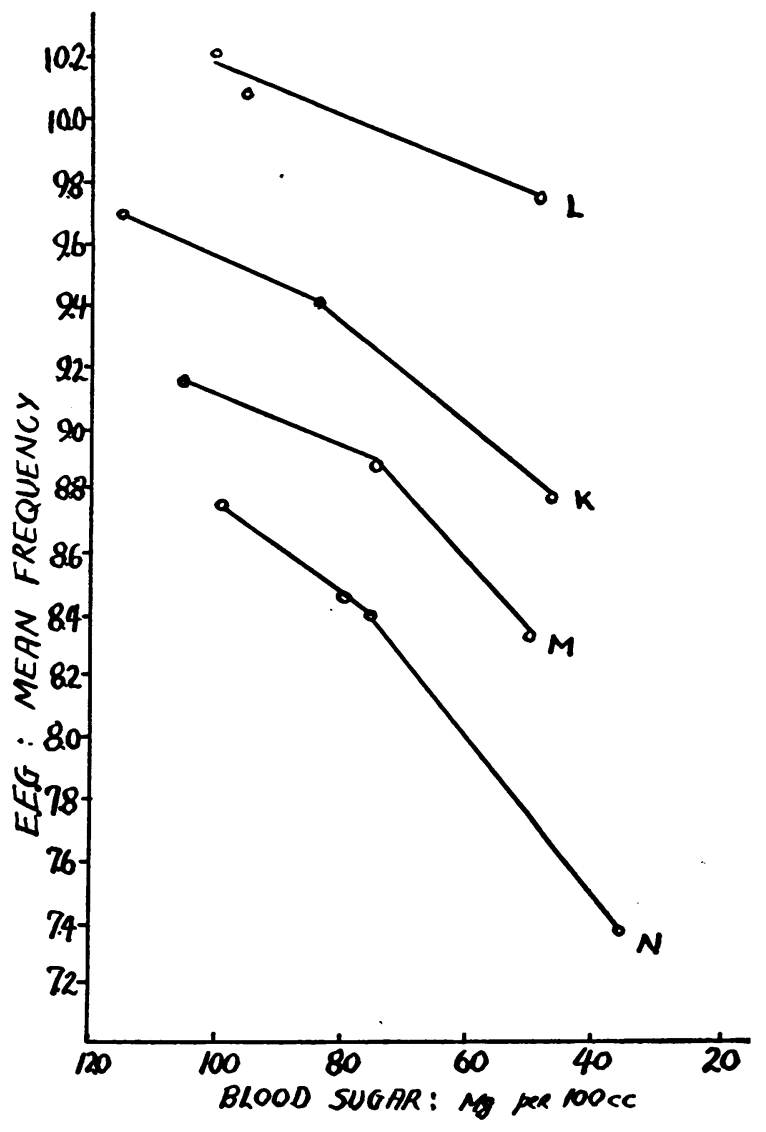

Fig. 5. Changes in Electroencephalographic Mean Frequency During Reduction of Blood Sugar to from 36 to 49 Mgm. Per Cent (same subjects as in previous FIGURES)

assurance as to the outcome of the experiment. In all instances, the degree of disturbance in consciousness, as closely as it could be assayed clinically and by the serial subtraction test was roughly comparable. It is clear from these observations that certain emotional factors played an important rôle in determining the behavior patterns. To these subjects, high altitude exposure was a familiar experience which provoked little anxiety, and was handled with confidence and assurance. During the alcoholic intoxication their behavior was conditioned by certain familiar social patterns and by previous experience. Hypoglycemia, on the other hand, a new and unfamiliar experience to all, provoked more anxiety than any of the other procedures. The reactions during comparable degrees of disturbance in the level of consciousness (relatively mild in these cases) and com- 
parable degree of electroencephalographic change are thus dependent both on the previous personality structure of the individual and on the psychologic and emotional significance of the particular experience.

\section{COM MENT}

These studies indicate that measurable changes in the electroencephalogram are demonstrable at an altitude of 10,000 feet $(522.6 \mathrm{~mm}$. $\mathrm{Hg})$ and increase progressively with the fall in atmospheric pressure. This change is not apparent on inspection alone. At 16,000 feet $(411.8 \mathrm{~mm}$. $\mathrm{Hg})$ the degree of change had attained a magnitude comparable to that seen during the earliest phase of acute alcoholic intoxication, and comparable to that seen upon reduction in blood sugar to levels of 40 to $49 \mathrm{mgm}$. per cent. Such a state is probably incompatible with maximum efficiency, even though some individuals may be able to compensate by heightened effort. It is important, too, that the change is apparent in as short a time as 5 minutes. The degree of change at 10,000 feet $(522.6 \mathrm{~mm} . \mathrm{Hg})$ was still within the range found among normal individuals during variations of blood sugar from 72 to $140 \mathrm{mgm}$. per cent and hence must be considered within physiological range. It should be emphasized that these experiments were carried out at complete rest. Obviously, with physical exertion further changes may be anticipated. Further changes may also be anticipated with longer exposures.

These data confirm and extends previous observations on the nature of delirium $(1,3)$. The primary psychologic symptom of delirium is a decrease in the level of consciousness with increased fluctuation in the level of awareness. In spontaneous delirium occurring during the course of many different clinical conditions (1) and in acute reactions induced by ingestion of alcohol and other toxic materials (3) we have demonstrated close correlation between electroencephalographic changes and alterations in the level of consciousness. In both spontaneous and induced reactions the earliest change in the electroencephalogram is a shift toward slower frequencies with little or no change in regularity or voltage. The degree of anoxia studied in these experiments represents the earliest zone in which changes would be anticipated and it is obviously not possible to set any sharp line of demarcation, clinically or electroencephalographically, between normal and abnormal. The slowing of the brain waves, and with it the probable alteration in cortical function, is progressive, but individuals still vary widely in their ego strength and in their means of defense. The factors of ego strength, previous personality structure, the setting and meaning of the experience as well as the structural integrity of the nervous system, are obviously most important in these borderline zones, where they make the difference between whether or not the symptoms develop and efficiency is impaired. In more extreme zones the changes in consciousness are readily demonstrable in all people.

These studies also demonstrate the great value of the electroencephalogram as an objective method of studying the effects of noxious influences on the cortex. In different individuals the degree of change in electroencephalographic mean frequency tended to be quite similar under comparable circumstances even though behavior varied considerably among the different individuals and in the different experimental circumstances. The degree of change in the level of consciousness, however, was, in so far as it could be estimated, similar in all subjects. This correlation has been brought out more clearly in studies which concerned more marked disturbances in the level of consciousness $(1,3)$.

The consistency in the change in the electroencephalographic mean frequency makes possible the evaluation of noxious effects with relatively few subjects and allows for the delineation of safe zones. This is of particular value in problems of military, aviation and industrial medicine where optimum performance is often required in spite of exposure to low oxygen tensions, to noxious gases (carbon monoxide, volatile gases, etc.) or to prophylactic drugs (sulfonamides, antimalarial drugs, etc.). Unpublished studies indicate that stimulant as well as depressant effects may be studied by this technique (3).

\section{SUM MARY}

1. Significant changes in frequency distribution of the electroencephalogram are demonstrable at altitudes of 10,000 feet and increase progressively 
with further increases in altitude. The changes are present within 5 minutes of reaching altitude, are fully developed within 15 minutes, and thereafter do not increase significantly up to 3 hours. Upon return to the ground, the electroencephalogram usually returns to base line status within 10 minutes.

2. The degree of change for each altitude could be reproduced in each subject on repeated examinations. At each altitude the degree of change was approximately the same for all individuals. The electroencephalograms with higher frequencies tended to show greater frequency shifts under comparable conditions.

3. The degree of frequency change at 39,000 feet breathing 100 per cent oxygen with the constant flow system was the same as that found at 10,000 feet breathing air; 42,500 feet breathing 100 per cent oxygen was the same as 16,000 feet breathing air.

4. Acute alcoholic intoxication of a degree likely to be experienced by most healthy individuals drinking socially provoked electroencephalographic changes roughly equivalent to those found at 16,000 feet. Severe intoxication produced more marked changes.

5. Reduction of blood sugar to levels of 44 to $49 \mathrm{mgm}$. per cent also provoked changes in the electroencephalogram roughly equivalent to that seen at 16,000 feet.
6. The behavior pattern of the same subjects experiencing equivalent degrees of disturbance in consciousness and equivalent electroencephalographic changes during anoxia, hypoglycemia, and acute alcoholic intoxication was found to vary considerably. This variation was related to the previous personality structure of the subject and the social and psychologic implications of the particular experimental procedures.

\section{BIBLIOGRAPHY}

1. Romano, J., and Engel, G. L., Studies of delirium. I. Electroencephalographic data. Arch. Neurol. and Psychiat., 1944, 51, 356.

Engel, G. L., and Romano, J., Studies of delirium. II. Reversibility of the electroencephalogram with experimental procedures. Arch. Neurol. and Psychiat., 1944, 51, 378.

2. Engel, G. L., Romano, J., Ferris, E. B., Webb, J. P., and Stevens, J. P., Simple method of determining frequency spectrums in the electroencephalogram: observation on effects of physiologic variations in dextrose, oxygen, posture and acid-base balance on the normal electroencephalogram. Arch. Neurol. and Psychiat., 1944, 51, 134.

3. Engel, G. L., and Rosenbaum, M., Delirium. III. Electroencephalographic changes associated with acute alcoholic intoxication. Arch. Neurol. and Psychiat., 1945, 53, 44.

Engel, G. L., Romano, J., and Ferris, E. B., Unpublished data.

4. Engel, G. L., Romano, J., Webb, J. P., Ferris, E. B., Ryder, H. W., and Blankenhorn, M. A., Unpublished data. 